\title{
Study on Displacement-based Design Method for Structures with Buckling Restrained Brace: Security and Seismic Design
}

\author{
Changhao Zhang ${ }^{1}$, Wei Wang ${ }^{2}$ and Jianhu Feng ${ }^{1}$ \\ ${ }^{1}$ College of Science, Chang'an University, Xi'an 710064, Shaanxi, China \\ ${ }^{2}$ Shandong Tong Yuan Design Group Co., Ltd., Jinan 250101, Shandong, China \\ zch0825@sina.com
}

\begin{abstract}
According to the mechanical performance and energy dissipation characteristics of buckling restrained brace, combined with the seismic design idea of code for seismic design of buildings(GB 50011 -2010), we put forward the displacement-based design method for structures with buckling restrained brace. In this paper, we analyze the seismic design of high-rise buildings and test the relationship between structural target displacement and BRB added stiffness for a single-degree-reedom system. By using an engineering example to verify the validity of the design method, the time history analysis results to elastic and elastic-plastic show that the displacement of BRB frame structure under frequent earthquake can reach the expected target displacement, under rare earthquake, the input energy are dissipated by BRB, improving the seismic capacity and safety reserves.
\end{abstract}

Keywords: Buckling restrained braces, Additional stiffness, Time history analysis, Seismic energy dissipation

\section{Introduction}

BRBs due to effective restraint external constraint element, avoid core plate unit under the pressure of buckling failure, and it has the advantages of simple structure, stability and seismic capacity, in the domestic and foreign new and widely used in the reinforcement engineering[1-2]. Generally, according to the different performance requirements of buckling restrained brace under earthquake action, the buckling restrained brace can be divided into three categories, namely, the energy dissipation type buckling restrained brace, the load bearing type buckling restrained brace, and the damping type buckling restrained brace. At present, engineering commonly used anti buckling support brace for the energy type[3-4], this type of support for maintaining the flexible work under small earthquake, only the lateral stiffness of the structure, the fortification and rare earthquake yielding, provide additional damping for structure. According to the mechanical behavior and energy dissipation characteristics of this type of BRBs, the BRB structure design method of stiffness based on demand, and on using the method of engineering design is to proceed the analysis, to verify and validate the method.

\section{Structural Target Displacement and Derivation of the Relationship between Additional Stiffness of BRB}

Because the elastic deformation of the structure is related to the lateral stiffness of the structure under earthquake, the displacement response of the structure can be controlled by adjusting the anti side of the structure. Remember the displacement of equivalent single degree of freedom system is not set BRBs under earthquake $U_{1}$ earthquake force corresponding to the $\mathrm{F}_{1}$, the lateral stiffness of $\mathrm{K}_{1}$, target displacement of equivalent SDOF system is equipped with anti buckling support after the earthquake force is $U_{2}$, 
corresponding to $\mathrm{F}_{2}$, the lateral stiffness is $\mathrm{K}_{2}=\mathrm{K}_{1}+\Delta \mathrm{K}, \Delta \mathrm{K}$ BRB added to the structure of the elastic lateral stiffness, the quality of the two systems were $\mathrm{m}$, specific parameters are shown in Figure 1. Figure 1(a) as not set BRB equivalent single degree of freedom system, Figure 1(b) means set BRB equivalent single degree of freedom system.

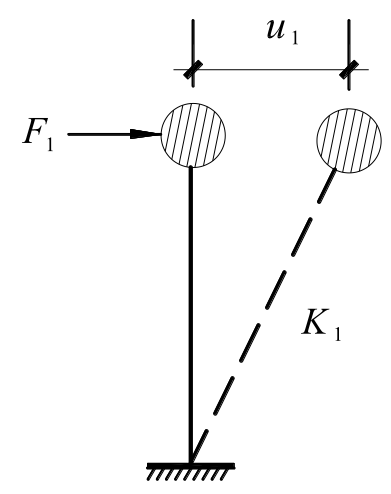

(a)

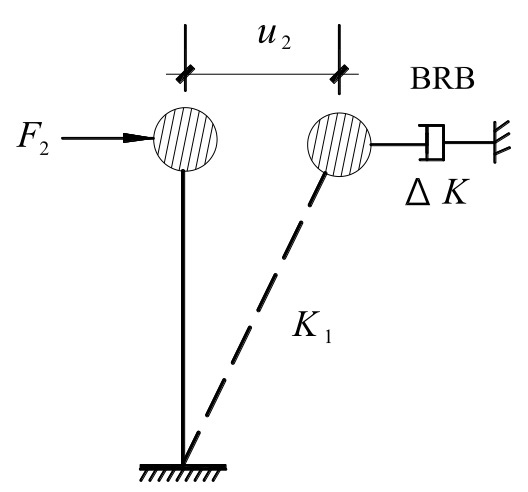

(b)

Figure 1.Schematic Diagram for Equivalent Single Degree of Freedom System

For the equivalent single degree of freedom system without BRB, the basic period of $\mathrm{T}_{1}$ is:

$$
T_{1}=2 \pi \sqrt{\frac{m}{K_{1}}}
$$

The basic period $T_{2}$ of the equivalent single degree of freedom system after setting BRB is:

$T_{2}=2 \pi \sqrt{\frac{m}{K_{1}+\Delta K}}=2 \pi \sqrt{\frac{m}{K_{2}}}$

Because of the "anti regulation", the seismic design method based on the small earthquake flexibility is adopted. Therefore, the structure has a linear relationship with the deformation under the action of earthquake:

$F_{i}=K_{i} \cdot u_{i} \quad(i=1,2)$

For the single degree of freedom system, it can be used to calculate the earthquake force under the earthquake action:

$F_{i}=\alpha_{i} G_{\mathrm{eq}}$

In the form, $\alpha_{i}$ is the seismic effect coefficient corresponding to the basic period of the single degree of freedom system, and the $G_{\text {eq }}$ is the representative value of the gravity load of the single degree of freedom system.

Because of the structure in the creation of BRB after the lateral stiffness is increased, so the vibration cycle is reduced, which is $\mathrm{T}_{1}>\mathrm{T}_{2}$, the reinforced concrete frame structure, the basic $\mathrm{T}_{1}$ cycle is mostly in the response spectrum curve of exponential decay, namely $T_{1} \in\left[T_{\mathrm{g}}, 5 T_{\mathrm{g}}\right]$ cycle range, but the addition of $\mathrm{BRB}$, the basic structure of $\mathrm{T}_{2}$ may be in a cycle the response spectrum curve of exponential decay, may also in the platform period of response spectrum curve, namely $T_{2} \in\left[0.1, T_{\mathrm{g}}\right]$ or $T_{2} \in\left[T_{\mathrm{g}}, 5 T_{\mathrm{g}}\right]$, therefore, the following 
points of the above two cases to discuss the target BRB structure and BRB structure attached to the elastic displacement relationship of stiffness.

\section{1. $T_{1} \in\left[T_{\mathrm{g}}, 5 T_{\mathrm{g}}\right], T_{2} \in\left[0.1, T_{\mathrm{g}}\right]$ and BRB Target Displacement Attached Stiffness Correlation}

When the basic cycle of $T_{1} \in\left[T_{\mathrm{g}}, 5 T_{\mathrm{g}}\right]$, set the BRB after basic period structure $T_{2} \in\left[0.1, T_{\mathrm{g}}\right]$, according to the "anti regulation" response spectrum curves corresponding to easy to obtain the basic period structure of $T_{1}$ and $T_{2}$ of the earthquake influence coefficient $\alpha_{1}$ and $\alpha_{2}$ :

$$
\begin{aligned}
& \alpha_{1}=\left(\frac{T_{g}}{T_{1}}\right)^{\left(0.9+\frac{0.05-\zeta}{0.3+6 \zeta}\right)} \cdot\left(1+\frac{0.05-\zeta}{0.08+1.6 \zeta}\right) \cdot \alpha_{\text {max }} \\
& \alpha_{2}=\left(1+\frac{0.05-\zeta}{0.08+1.6 \zeta}\right) \cdot \alpha_{\text {max }}
\end{aligned}
$$

The formula: $\zeta$ the structural damping ratio for reinforced concrete structures can be 0.05 .

Simultaneous formula (1) (6) available:

$$
\frac{F_{2}}{F_{1}}=\frac{K_{2} u_{2}}{K_{1} u_{1}}=\frac{K_{2} \theta_{2} h}{K_{1} \theta_{1} h}=\frac{\alpha_{2} G_{\mathrm{eq}}}{\alpha_{1} G_{\mathrm{eq}}}=\left(\frac{2 \pi \sqrt{\left(m / K_{1}\right)}}{T_{g}}\right)^{\left(0.9+\frac{0.05-\zeta}{0.3+6 \zeta}\right)}
$$

In the formula: $\theta_{1}$ and $\theta_{2}$ respectively for the BRB structure is not set the layer displacement angle and set up the BRB after the inter storey displacement angle, $h$ as floor height.

Simplified formula (7) can get the correlation between structural target displacement and the elastic stiffness of BRB attached to the structure:

$$
\Delta K=\frac{\left(\frac{2 \pi \sqrt{\left(m / K_{1}\right)}}{T_{g}}\right)^{\left(0.9+\frac{0.05-\zeta}{0.3+6 \zeta}\right)} \cdot K_{1} \theta_{1}}{\theta_{2}}-K_{1}
$$

Formula (8) is in the determination of target displacement $u_{2}=\theta_{2} h$, required BRB to the calculation of lateral stiffness of structure.

\section{2. $T_{1} \in\left[T_{g}, 5 T_{g}\right], T_{2} \in\left[T_{g}, 5 T_{g}\right]$ and $B R B$ Target Displacement Attached Stiffness Correlation}

When the basic cycle of $T_{1} \in\left[T_{\mathrm{g}}, 5 T_{\mathrm{g}}\right]$, set the BRB T2 after basic period structure of $T_{2} \in\left[T_{\mathrm{g}}, 5 T_{\mathrm{g}}\right]$, according to the "anti regulation" of the response spectrum curve can also be obtained corresponding to the basic structure of $T_{1}$ and $T_{2}$ of the periodic earthquake influence coefficient $\alpha_{1}$ and $\alpha_{2}$, similar to the relationship of the structure of the target. $\mathrm{BRB}$ added to the structure displacement and elastic stiffness between the:

$$
\Delta K=K_{1}\left(\theta_{1} / \theta_{2}\right)^{\frac{2.0 .9+\frac{0.05-\zeta}{0.3+6 \zeta}}{(0.5}}-K_{1}
$$

The required $\mathrm{BRB}$ provided by the target displacement of the additional lateral stiffness, can be calculated by the required $\mathrm{BRB}$ to provide the axial stiffness of $\mathrm{Kb}$, 
which can be calculated according to the specific parameters of the BRB number of BRB required.

$K_{\mathrm{b}}=\frac{\Delta K}{\cos ^{2} \theta}$

Formula (8) and (9) in the target displacement and BRB additional stiffness correlation curve see Figure 2, can be seen from the figure, when the structure added after BRB due to stiffness increase, thereby reducing the displacement response of the structure, the structure of BRB required to reduce additional stiffness displacement with the structure of the target. But, showed the characteristics of nonlinear change.

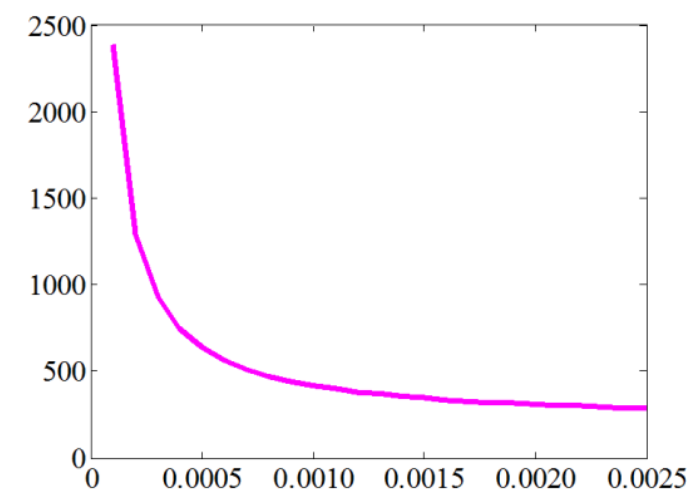

(a) $T_{1} \in\left[T_{g}, 5 T_{g}\right], T_{2} \in\left[0.1, T_{g}\right]$

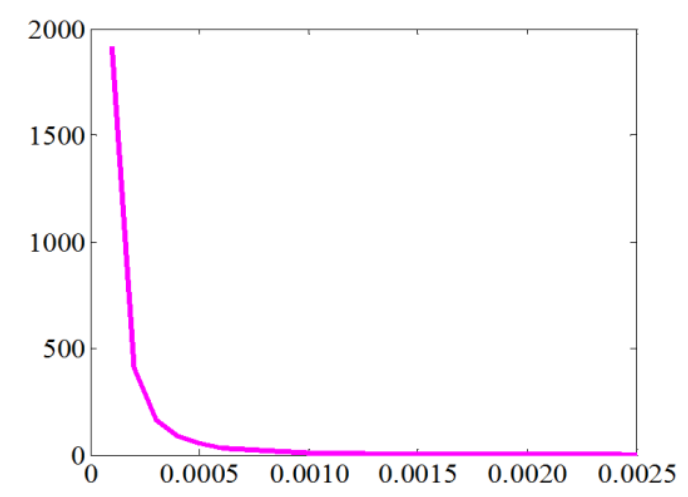

(b) $T_{1} \in\left[T_{g}, 5 T_{g}\right], T_{2} \in\left[T_{g}, 5 T_{g}\right]$

Figure 2. Curve between Structural Target Displacement and BRB added Stiffness

\section{Engineering Case Analysis}

\subsection{Engineering Survey}

A reinforced concrete structure is shown in Figure 3, the project covers an area of $352 \mathrm{~m}^{2}$, total construction area of $2300 \mathrm{~m}^{2}$, the main structure of 7 layers, the height of the first floor is $3.6 \mathrm{~m}$, the rest of the floor height is $3.0 \mathrm{~m}$, the total height is $21.6 \mathrm{~m}$, the construction site for the II category, the design for the second earthquake group, the characteristic period of the site $0.4 \mathrm{~s}$, seismic intensity of 8 degrees, $0.2 \mathrm{~g}$, design basic earthquake acceleration the grade of R.C.Frame seismic grade two. The new version of the old building because of "anti regulation" alternately, enhance the level of seismic level, seismic performance can not meet the requirements of current seismic codes, to seismic 
reinforcement design, we use BRB to the original structure reinforcement design of damping energy dissipation.

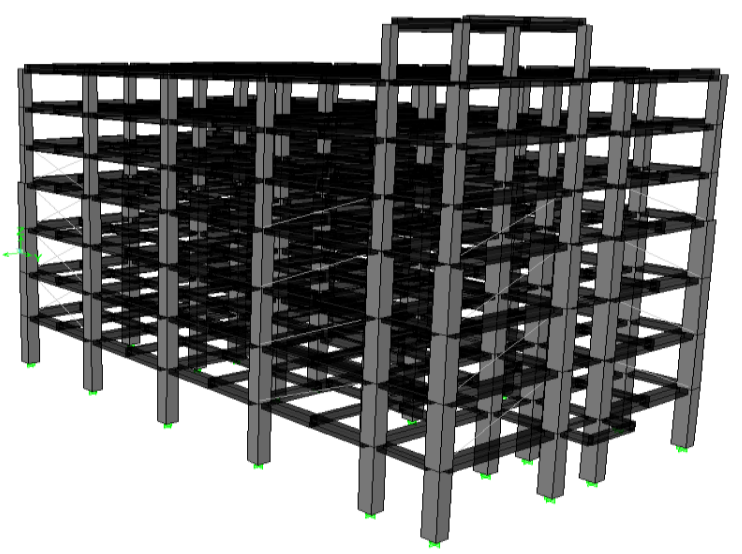

Figure 3. Sketch of Space Structure Model

\subsection{Calculation of the Additional Stiffness of BRB under the Target Displacement}

According to the design method mentioned above, the structure of each floor is approximately equivalent to a single degree of freedom, first determine the basic parameters of the structure reinforcement, including total quality structure, the floor displacement angle in two axis direction between layers and floor lateral stiffness, the interlayer displacement angle can be calculated by modal spectrum method the decomposition reaction of floor lateral stiffness by D value method[5], BRB strengthened target inter storey displacement angle is $1 / 650$, the calculation to the basic parameters of the structure without reinforcement and BRB required additional stiffness are shown in Table 1.

Table 1. Basic Parameters of Un-reinforced Structure

\begin{tabular}{cccccccccc}
\hline \multirow{2}{*}{ floor } & $\begin{array}{c}\text { Quality } \\
\mathrm{m} / \text { ton }\end{array}$ & \multicolumn{2}{c}{$\begin{array}{c}\text { Inter layer drift } \\
\text { angle }\end{array} \theta_{1} / \mathrm{rad}$} \\
\cline { 2 - 9 } & & \multicolumn{2}{c}{$\begin{array}{c}\text { Lateral stiffness of } \\
\text { storey } \mathrm{K}_{1} /\end{array}$} & \multicolumn{2}{c}{$\begin{array}{c}\text { Additional lateral } \\
\text { stiffness } \Delta \mathrm{K} / \mathrm{mm})\end{array}$} & $\begin{array}{c}\text { Additional axial } \\
(\mathrm{kN} / \mathrm{mm})\end{array}$ & $\begin{array}{c}\text { Adiffness } \mathrm{Kb} / \\
(\mathrm{kN} / \mathrm{mm})\end{array}$ \\
\hline 7 & 918 & $1 / 1032$ & $1 / 1120$ & 1015 & 1135 & -452 & -386 & -639 & -546 \\
6 & 902 & $1 / 732$ & $1 / 757$ & 1028 & 1253 & -26 & -19 & -37 & -27 \\
5 & 902 & $1 / 633$ & $1 / 652$ & 1137 & 1296 & 3 & -0.2 & 4 & -0.3 \\
4 & 1006 & $1 / 585$ & $1 / 600$ & 1411 & 1489 & 900 & 805 & 1273 & 1139 \\
3 & 1006 & $1 / 536$ & $1 / 547$ & 1469 & 1507 & 1100 & 964 & 1556 & 1364 \\
2 & 1011 & $1 / 551$ & $1 / 570$ & 1438 & 1523 & 972 & 837 & 1375 & 1184 \\
1 & 1030 & $1 / 967$ & $1 / 1065$ & 1632 & 1709 & -730 & -665 & -1033 & -941 \\
\hline
\end{tabular}

From Table 1, we can get that no reinforcement structure in the $\mathrm{X}$ layer to the $\mathrm{Y}$ to the maximum and drift angle are respectively $1 / 536$ and $1 / 547$, do not satisfy the "anti regulation" of frame structure under small earthquake drift angle, this is due to the stiffness requirements without reinforcement structure under earthquake is large, and the original structure is relatively flexible, so the deformation is too large, so the use of BRB to increase the lateral stiffness of the structure, in order to improve its ability to resist deformation, in the target $1 / 650$ interlayer displacement, BRB required to provide additional specific numerical stiffness is shown in Table 1, table in the negative, that of the floor displacement has reached the target displacement, without adding BRB, according to the list of additional axial stiffness values, selection for BRB, considering the 
structure of the building function and performance goals, determined after analysis, this project adopts 4 types of BRB, a total of 24, Specific parameters and layout see Table 2.

Table 2. Basic Parameters and Layout of BRB

\begin{tabular}{|c|c|c|c|c|c|c|c|}
\hline $\begin{array}{l}\text { BRB } \\
\text { number }\end{array}$ & $\begin{array}{l}\text { Support } \\
\text { length } \\
1 / \mathrm{mm}\end{array}$ & $\begin{array}{c}\text { Core } \\
\text { strength } \\
\mathrm{f}_{\mathrm{y}} / \mathrm{MPa}\end{array}$ & $\begin{array}{c}\text { Yield } \\
\text { bearing } \\
\text { capacity } \\
\mathrm{F}_{\mathrm{y}} / \mathrm{kN}\end{array}$ & $\begin{array}{c}\text { Post } \\
\text { yield } \\
\text { stiffness } \\
\text { ratio } \beta\end{array}$ & $\begin{array}{c}\text { Yield } \\
\text { displacement } \\
\mathrm{D}_{\mathrm{y}} / \mathrm{mm}\end{array}$ & $\begin{array}{c}\text { Limit } \\
\text { displacement } \\
\mathrm{Du} / \mathrm{mm}\end{array}$ & $\begin{array}{c}\text { Layout } \\
\text { position }\end{array}$ \\
\hline BRB 1 & 6500 & 235 & 700 & 0.02 & 3.6 & 58.3 & $\begin{array}{c}2 \text { layer } \\
\mathrm{X} \\
\text { direction } \\
3,4\end{array}$ \\
\hline BRB 2 & 6500 & 235 & 500 & 0.02 & 3.6 & 58.3 & $\begin{array}{l}\text { layer } \mathrm{X} \\
\text { direction }\end{array}$ \\
\hline BRB 3 & 8000 & 235 & 700 & 0.02 & 4.2 & 67.6 & $\begin{array}{c}2 \text { layer } \\
\mathrm{Y} \\
\text { direction } \\
3,4\end{array}$ \\
\hline BRB 4 & 8000 & 235 & 500 & 0.02 & 4.2 & 67.6 & $\begin{array}{l}\text { layer Y } \\
\text { direction }\end{array}$ \\
\hline
\end{tabular}

\subsection{Elastic Time History Analysis under Earthquake}

In order to verify the above design method, the displacement of the structure with enough structure under earthquake action is to reach the target displacement, and the elastic time history analysis of the BRB reinforced structure under earthquake action is carried out. According to the "code for seismic design of buildings GB50011-2010[6] requirements, based on site classification, peak ground acceleration, effective duration and spectrum characteristics, choose match the conditions of 2 natural waves and 1 artificial wave as the seismic input, the natural wave basic information is shown in Table 3 , the earthquake under the condition of standard response spectrum response and the seismic wave spectrum curve is shown in Figure 4. In the process of analysis, the peak value of seismic wave acceleration is adjusted to $70 \mathrm{~cm} / \mathrm{s}^{2}$.

Table 3. Natural Seismic Wave Information

\begin{tabular}{|c|c|c|c|c|c|}
\hline \multicolumn{2}{|r|}{ Seismic wave number } & \multirow[b]{2}{*}{ wave form } & \multirow{2}{*}{$\begin{array}{l}\text { Occurrence } \\
\text { time }\end{array}$} & \multirow{2}{*}{$\begin{array}{l}\text { Seismic } \\
\text { name }\end{array}$} & \multirow[b]{2}{*}{ Recording station } \\
\hline $\begin{array}{l}\text { Present } \\
\text { number }\end{array}$ & Original number & & & & \\
\hline $\mathrm{T} 1$ & 3439CHICHI06.TCU003 & 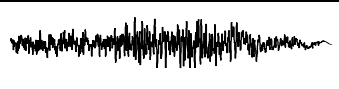 & $\begin{array}{c}\text { September } \\
21,1999\end{array}$ & $\begin{array}{l}\text { Chi-Chi } \\
\text { earthquake }\end{array}$ & TCU005,CHICHI \\
\hline $\mathrm{T} 2$ & 76SFERN.MA3 & 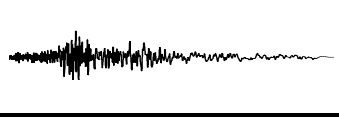 & $\begin{array}{c}\text { February } \\
9,1971\end{array}$ & $\begin{array}{c}\text { San } \\
\text { Fernando } \\
\text { earthquake }\end{array}$ & $\begin{array}{c}\text { Maricopa Array } \\
\# 3 \\
\end{array}$ \\
\hline
\end{tabular}




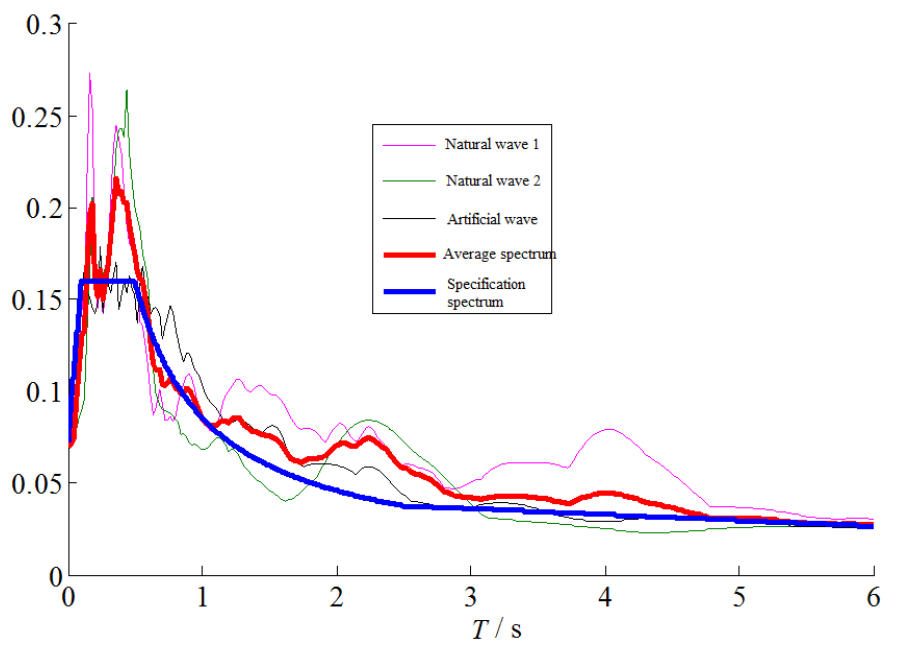

Figure 4. Response Spectrum of Frequent Earthquake

3.3.1. Analysis of Shear Force and Displacement of Reinforced Concrete Structure after BRB: Figure 5 in order to use the above design method to design the structure of the BRB reinforced structure under the 3 seismic wave multi case earthquake action under the layer displacement angle curve distribution. It can be seen from the figure, the 3 seismic waves, $\mathrm{X}$ structure and $\mathrm{Y}$ floor displacement of the envelope value reached the target set the displacement angle between 1/650, two axis displacement response are produced in natural wave under the action of 1 of the largest, the largest $X$ layer to drift into $1 / 658$, the largest $\mathrm{Y}$ layer to the drift angle is $1 / 669$, meet the "anti regulation" of frame structures in the earthquake deformation under earthquake.

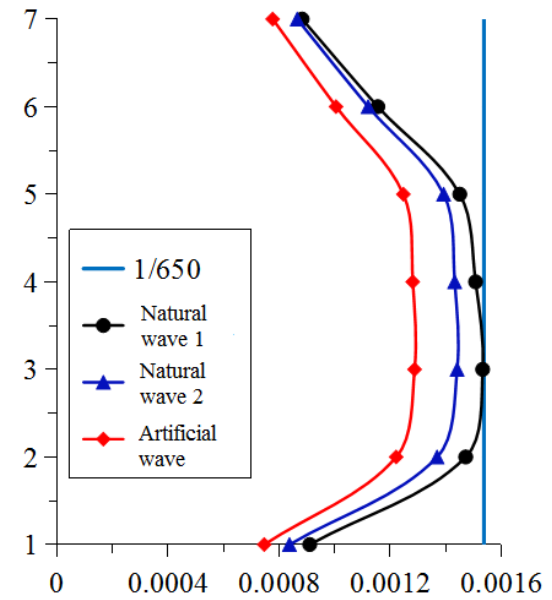

(a) X displacement angle

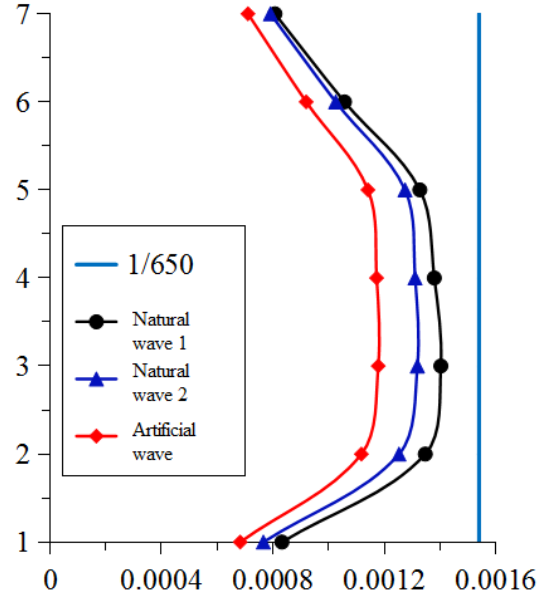

(b) Y displacement angle

Figure 5. Inter-story Drift of Reinforced Structure with BRB

In addition due to the structural buckling after its lateral stiffness increases, the structure of seismic demand will increase, but the total seismic force under each floor structure borne by the frame part and the BRB part of the seismic force combination, therefore, it is necessary to examine the structure under seismic force distribution after the addition of BRB. Figure 6 for the structure in 3 earthquake waves under the earthquake action, BRB share the seismic shear and the total floor of the total shear ratio. As can be seen from the figure, $\mathrm{X}$ and $\mathrm{BRB}$ to the lower part of the floor to share the seismic shear ratio of the upper floors slightly larger, $\mathrm{X}$ and $\mathrm{Y}$ to the second storey BRB share of the 
seismic shear up to about $48 \%$ and $39 \%$ respectively. Although the structure in the creation of $\mathrm{BRB}$ after the earthquake shear force increased, but the BRB share part of the earthquake force, seismic force on the part of the frame column is only a slight increase, thus improving the seismic safety of reserve capacity in the structure under the action of earthquake[7].
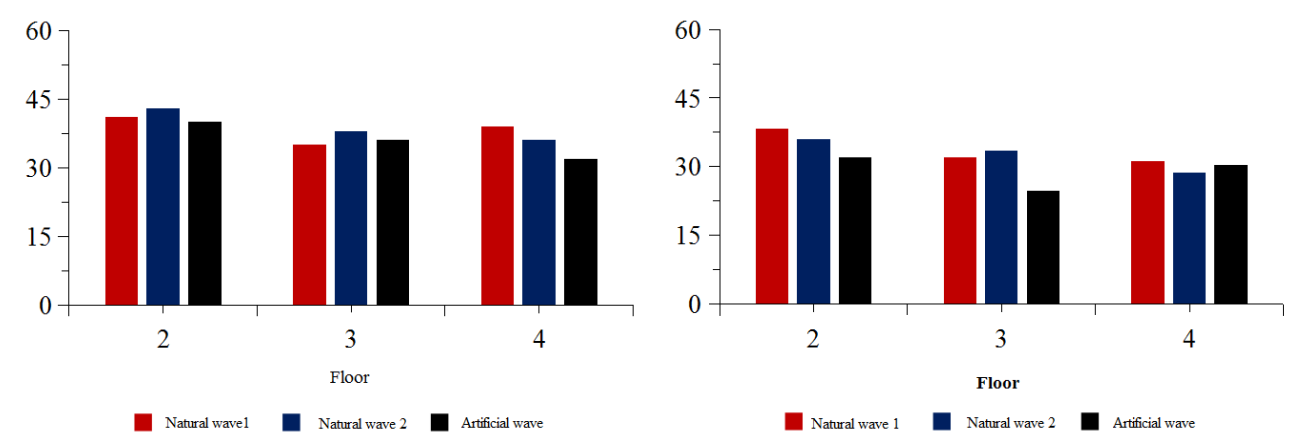

Figure 6. Ratio of Buckling Restrained Braces Share the Story Shear Force

3.3.2. Energy Distribution Analysis of BRB Strengthened Structure: After adding $\mathrm{BRB}$, the dynamic characteristics of the structure are changed, so the energy and its distribution of the seismic input structure will be investigated, which will be beneficial to the safety of the structure under earthquake action. Figure $7 \mathrm{a}, 7 \mathrm{~b}$ is a typical BRB under small earthquake hysteretic curve of the $7 \mathrm{C}$ for the energy distribution of structure under earthquake, the hysteretic curve can be seen as the earthquake, $\mathrm{X}$ to the maximum axial force of BRB $388 \mathrm{kN}$, Y BRB to the maximum axial force is $639 \mathrm{kN}$. Are less than the yield capacity, indicating that BRB was almost in the elastic stage, only the lateral stiffness of the structure, to resist under earthquake large deformation, energy distribution from curve can be seen, most of the seismic energy input structure is the structure damping dissipation, BRB almost no energy consumption.

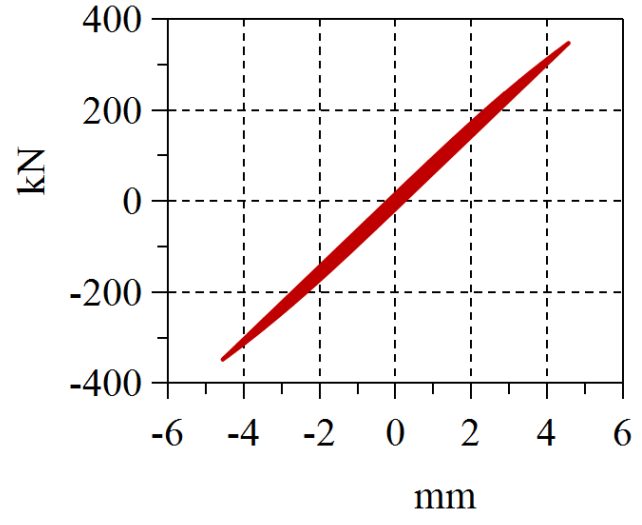

(a) BRB hysteresis curve of $X$

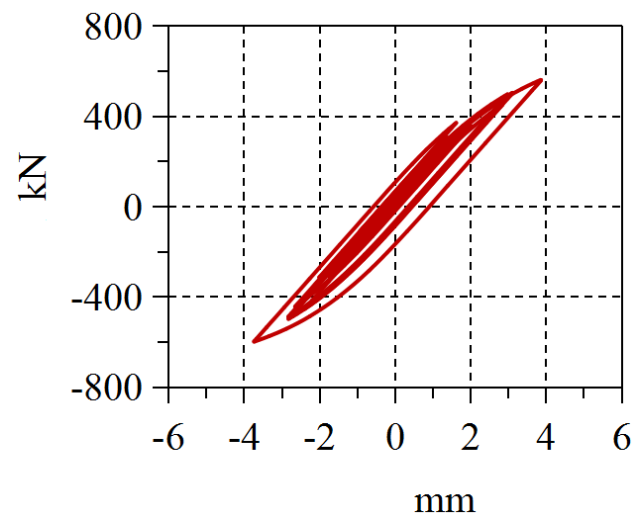

(b) BRB hysteresis curve of $Y$ 


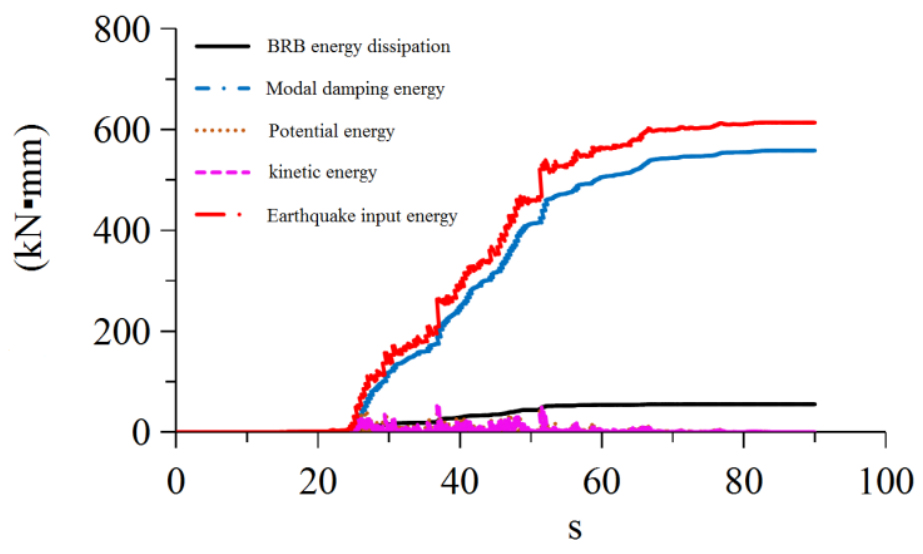

(c) energy distribution time history curve

Figure 7. Energy Analysis of Reinforced Structure under Frequent Earthquake

\subsection{Elastic Plastic Time History Analysis under the Action of Rare Earthquake}

In order to investigate the design method of the design of the energy dissipation structure in seismic performance under rare earthquake, using SAP2000 finite element software of BRB structure after reinforcement of elastic-plastic time history analysis model, in the framework of the Liang Zhu part of the elastoplastic properties of the hinge moment of program default (M3) and axial force moment correlation hinge (P-M2-M3) to consider the nonlinear BRB proposed by Wen[8] in 1976 based on the connection element to simulate. Figure $8 \mathrm{X}$ and $\mathrm{Y} \mathrm{BRB}$ under rare earthquake hysteretic curve, from the shape, plump hysteretic curve, shows its energy dissipation capacity stably. The maximum axial force X to BRB to $591 \mathrm{kN}$, Y to the maximum axial force BRB is $784 \mathrm{kN}$, BRB into the elastic-plastic the work stage, the seismic energy dissipation structure, become the first seismic line. Figure 9 is a rare case in the structure of the plastic hinge distribution under the action of earthquake, can be seen from the figure, $\mathrm{X}$ and $\mathrm{Y}$ were involved in the overall structure of the elastic-plastic stage, the yield mechanism for frame beam column yield first, then, the overall performance is yielding sequence of strong column and weak beam ", built seismic concept design requirements, and the components are in slight plastic, namely the first plastic stage (IO stage), slight structural damage, after the repair can continue to use.

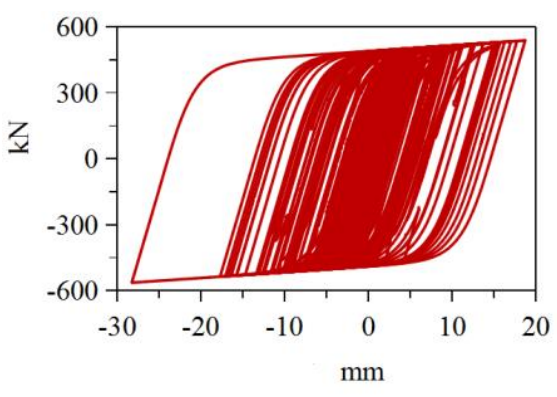

(a) BRB hysteresis of $X$

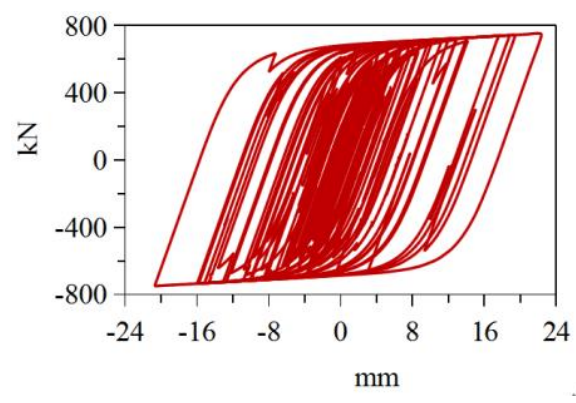

(b) BRB hysteresis of $Y$

Figure 8. Typical Hysteretic Loops of Buckling Restrained Brace under Rare Earthquake 


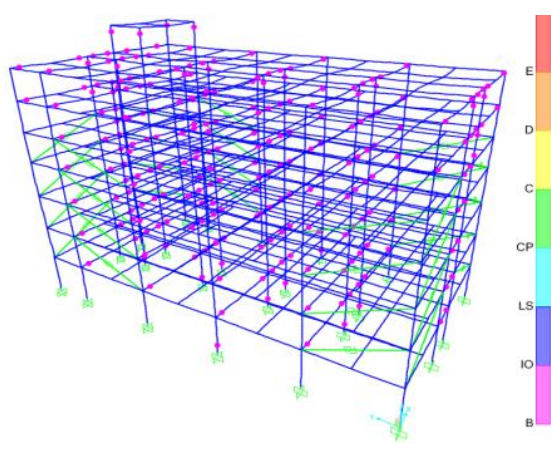

(a) structure of $X$

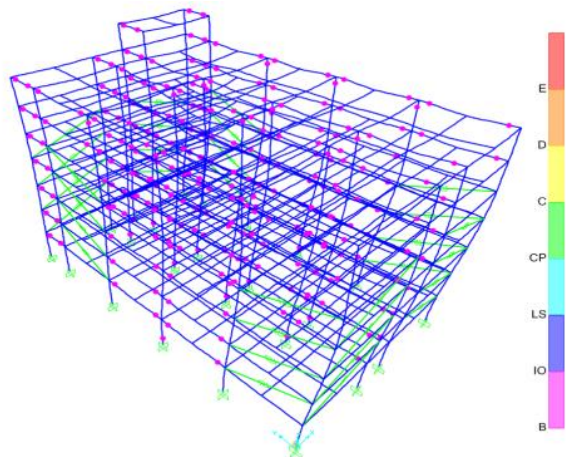

(b) structure of $Y$

Figure 9. Plastic Hinge Distribution of Structure

\section{Conclusion}

In this paper, the equivalent single degree of freedom system are derived based on the deformation of structure and BRB relationship between the additional stiffness, and gives the design method of BRB structure based on displacement, and the correctness of an engineering example to verify the design method, obtained the following conclusions:(1) under the action of earthquake, the additional stiffness of the structure is increased with the decrease of the target displacement of the structure, and the relationship between the BRB added stiffness and the structure is nonlinear.(2) shows that the analysis results frequent seismic action, the design method of the BRB structure of the target displacement based on BRB is accurate and reliable, the actual reinforcement displacement structure under earthquake reached the target displacement, and satisfy the deformation limit value requirements specification.(3) in case of earthquake, the maximum ratio of BRB in the two main axes of the structure is $48 \%$ and $39 \%$, which forms a dual lateral force resisting system.(4) under the rare earthquake elastoplastic analysis results show that the BRB yield, provide additional damping for structure, effectively dissipate seismic energy, yield structure in order to show "strong column and weak beam", a reasonable yield mechanism.

\section{References}

[1] Z. Yun, "Structural design and application of buckling-restrained brace", Beijing: China Architecture \& Building, (2007), pp. 55-60.

[2] W. Guixuan and W. Yu, "Analysis of energy dissipation and earthquake mitigation of a high-rise building with metal dampers", World Earthquake Engineering, vol. 28, (2012), pp. 111-115.

[3] G. Xiangyu and D. Haiyan, "Experimental study on seismic performance of buckling restrained brace made of Q235 hot-rolled steel”, Building Structure, vol. 3, (2008), pp. 91- 95.

[4] G. Yanlin and L. Jianbin, "Structural energy dissipation and seismic mitigation method and bucklingrestrained brace", Building Structure, vol. 35, (2005), pp. 18-23.

[5] A. Chopra, "Dynamics of structures: theory and applications to earthquake engineering", Englewood Cliffs, (2012), pp. 27-40.

[6] GB 50011-2010 Code for seismic design of buildings. Beijing: China Architecture \& Building Press, (2010), pp. 12-15.

[7] Z. Yun and X. Zhaodong, "Optimal placement of the viscoelastic damping structure with dampers", World Eathquake Engineering, vol. 14, (1998), pp. 15-20.

[8] FEMA450. Nehrp recommended provisions for seismic regulations for new buildings and other structures. Washington D. C. Federal Emergency Management Agency, (2003), pp. 27-40. 